\title{
Design and Performance of Anticracking Asphalt-Treated Base
}

\author{
Xiaoge Tian, ${ }^{1}$ Haifeng Han, ${ }^{2}$ Qisen Zhang, ${ }^{1}$ Xinwei $\mathrm{Li}^{2}$, and $\mathrm{Ye} \mathrm{Li}^{1}$ \\ ${ }^{1}$ Changsha University of Science \& Technology, Changsha, Hunan 410114, China \\ ${ }^{2}$ Guangzhou Highway Co. Ltd., Guangzhou, Guangdong 760000, China \\ Correspondence should be addressed to Xiaoge Tian; tianxiaoge@126.com
}

Received 28 February 2017; Accepted 12 April 2017; Published 22 May 2017

Academic Editor: Hainian Wang

Copyright (C) 2017 Xiaoge Tian et al. This is an open access article distributed under the Creative Commons Attribution License, which permits unrestricted use, distribution, and reproduction in any medium, provided the original work is properly cited.

\begin{abstract}
To enhance the crack resistance of asphalt-treated base (ATB), a type of gapped and semiopened gradation ATB mixture, GSOG, was designed. Its design method was proposed based on the volume design method and performance tests. Firstly, several gradations were designed preliminarily in which middle particle sizes of coarse aggregates were partially or completely gapped according to the gradation specification. Secondly, their voids in coarse aggregates (VCA) were determined through dry rod compaction test on coarse aggregates, and then their theoretical voids were calculated. Gradations whose theoretical voids met the requirements were selected to fabricate specimens with Superpave Gyratory Compactor, and their voids were determined using vacuum sealing method and submerged weight in water method. Finally, gradations whose voids meet requirements were selected to fabricate different types of specimens for various performance tests, and the optimal gradation can be selected comprehensively considering their performances, especially focusing on their crack resistance. According to this gradation design method, the gradation of GSOG-25 was designed, and its performances, including high-temperature stability, water stability, fatigue, and antireflection crack resistance, were measured and compared to ordinary ATB-25. The results demonstrate that the performance of GSOG-25 is much better than that of ordinary ATB-25, especially in anticracking capacity.
\end{abstract}

\section{Introduction}

In China, semirigid inorganic binding material stabilized macadam was used as a base course in $95 \%$ of asphalt pavements $[1,2]$. The semirigid base course can objectively provide the necessary structural capacity for pavement under heavy traffic condition in our country. However, semirigid base course cracks easily because of its temperature shrinkage and/or dry shrinkage. The cracks in the base course will result in reflection cracks through asphalt pavement surface after being opened to traffic for only 1 or 2 years whether the pavement is in the frozen or unfrozen regions. Then water will penetrate into the pavement structure and will accelerate the destruction process of the pavement [3-5].

A thorough literature review revealed that extensive past research focused on characterizing and assessing ATB through laboratory evaluations [6-11], field investigations and validations [12-14], and empirical and mechanistic modeling $[15,16]$. Marjerison studied the mechanistic comparison of cement- and bituminous-stabilized granular base systems [17]. Schwartz and Khosravifar studied the design and evaluation of foamed asphalt base materials [18]. Wang put forward a performance-based mixture design of asphalt-treated base [19]. Li et al. studied the materials and temperature effects on the resilient response of asphalttreated alaskan base course materials [20]. Hector developed a new mix design method and specification requirements for asphalt-treated bases [21]. Zhang et al. studied the volumetric properties and permeability of asphalt-treated permeable base mixtures [22]. Haider et al. investigate the effects of HMA surface layer thickness, base type, base thickness, and drainage on the performance of new flexible pavements constructed in different site conditions (subgrade type and climate), and the data are from the SPS-1 experiment of the Long-Term Pavement Performance program. Base type was found to be the most critical design factor affecting fatigue cracking, roughness (IRI), and longitudinal cracking (wheel path). The best performance was shown by pavement sections with asphalt-treated bases [23].

In recent years, a layer of ATB was utilized between the semirigid base course and asphalt concrete layer to avoid or delay the reflective cracks. This is according to 
the structural and material characteristics of abroad longlasting asphalt pavement [1-4]. But reflection cracks had not been eliminated fundamentally $[3,4]$. The test pavement structure section constructed by Dong et al. demonstrated that ATB can effectively decrease the premature failure caused by reflection cracks [24]. Feng and Hao put forward a fivecontrol-points design method for dense gradation ATB, and the designed gradation was close to the gradation designed through CAVF method [25]. Zhesheng and Qian concluded that ATB has good mechanical and fatigue properties according to fatigue tests results conducted to ATB beams under different stress ratios [26]. Research results of Qian and Shu revealed that ATB with high viscosity hard asphalt ( $\mathrm{AH} 30$ ) is superior to the ATB with original asphalt (AH70) in hightemperature stability, water stability, and fatigue life [27].

So, the aim of this paper is to enhance the crack resistance of ATB. The gradation objective and design method were put forward on the anticracking ATB, which was called GSOG later. The gradation of this new kind of anticracking ATB, GSOG, is partially or completely gapped in middle particle size of coarse aggregates, and its void is $8 \%$ to $12 \%$, namely, semiopened. In order to compensate for the weakening of the bonding force between the coarse aggregates due to the increase of voids, SBS modified asphalt was used as the binder. Its gradation design method is based on the volume design method and performance tests. According to this GSOG design method, GSOG-25 was designed, and various performance tests were conducted and compared with the ordinary ATB-25. The tests results demonstrated that the performance of GSOG-25 is great and its antireflection cracking capacity is much better than the ordinary ATB. So, it can be used to prolong the service life of asphalt pavement structure.

\section{Gradation Design Method of the Anticracking ATB}

2.1. Basic Principles. In order to enhance the crack resistance of ATB, the solutions were put forward from two aspects of gradation and asphalt binder. They are given as follows.

(1) Regarding air voids, the voids in the mixture can eliminate or attenuate the stress concentration and extend the crack propagation path. So, a certain amount of voids can be used to enhance the crack resistance of the mixture. The mixture gradation can be designed as a semiopened gradation; namely, its void content is $8 \%$ to $12 \%$.

(2) As regards gradation, skeleton structure formed by squeezing of coarse aggregate can enhance the bearing capacity. So, coarse aggregates in the GSOG gradation should squeeze each other to form a stable skeleton to withstand the external load and maintain the stability of the material structure and enhance its high-temperature stability and deformation resistance $[28,29]$. To avoid the interference caused by the middle particle size to the coarse aggregate skeleton structure and ensure the stability of the coarse aggregate skeleton structure, the intermediate particle sizes ( $4.75 \mathrm{~mm}$ and/or $9.5 \mathrm{~mm}$ ) coarse aggregates were completely or partially gapped [30].

(3) For asphalt binder, considering that increasing porosity of the mixture will affect the bond between aggregates and will affect the performance and durability of the mixture, polymer modified asphalt can be used as the asphalt binder. The use of polymer modified asphalt can not only enhance the cohesion between aggregates but also increase the thickness of asphalt film and enhance its fatigue and cracking resistance. This will improve its durability.

(4) Concerning performance, the performances of designed GSOG, including high-temperature stability, lowtemperature crack resistance, water stability, fatigue resistance, and crack resistance, should meet the requirements or be better than the ordinary ATB.

2.2. Basis Procedures. According to the upper basic design principles, a gradation optimization method was put forward based on the volume design method [31] and performance tests. Its basic steps are given as follows.

(1) Several gradations with the intermediate particle sizes $(4.75 \mathrm{~mm}$ and/or $9.5 \mathrm{~mm}$ ) coarse aggregates gapped completely or partially were initially designed according to the gradation limits of ATB.

(2) The void of coarse aggregate, VCA, was determined through the dry-rodded compaction tests of coarse aggregates.

$$
\mathrm{VCA}=\left(\frac{1-\mathrm{GCA}_{\mathrm{DRC}}}{G_{\mathrm{b} . \mathrm{ca}}}\right),
$$

where VCA is the void of dry-rodded compacted coarse aggregates, \%; $\mathrm{GCA}_{\mathrm{DRC}}$ is the dry-rodded compacted density of coarse aggregates, $\mathrm{g} \cdot \mathrm{cm}^{-3}$; and $G_{\text {b.ca }}$ is the bulk density of coarse aggregates, $\mathrm{g} \cdot \mathrm{cm}^{-3}$.

(3) Calculate the air voids of each mixture at different asphalt aggregate ratio according to their gradations and densities of each aggregate.

$$
V_{\mathrm{a}}=\mathrm{VCA}-\frac{P_{\mathrm{fa}} / G_{\mathrm{b} . \mathrm{fa}}+P_{\mathrm{f}} / G_{\mathrm{a} . \mathrm{fi}}+P_{\mathrm{b}} / G_{\mathrm{b}}}{P_{\mathrm{ca}} / \mathrm{GCA}_{\mathrm{DRC}}},
$$

where $V_{\mathrm{a}}$ is the air void of asphalt mixture, $\% ; P_{\mathrm{b}}$ is the asphalt aggregate ratio, $\%$; $G_{\text {b.fa }}$ is the bulk density of fine aggregates, $\mathrm{g} \cdot \mathrm{cm}^{-3} ; G_{\text {a.fi }}$ is the apparent density of filler, $\mathrm{g} \cdot \mathrm{cm}^{-3} ; G_{\mathrm{b}}$ is the density of asphalt, $\mathrm{g} \cdot \mathrm{cm}^{-3} ; P_{\mathrm{ca}}$ is the mass fraction of coarse aggregate to all aggregates, $\% ; P_{\mathrm{fa}}$ is the mass fraction of fine aggregate to all aggregates, $\%$; and $P_{\mathrm{fi}}$ is the mass fraction of filler $(<0.075 \mathrm{~mm})$ to all aggregates, $\%$.

(4) Fabricate samples with Superpave Gyratory Compactor (SGC) for those gradations whose voids meet the requirements. Vacuum seal the samples with CoreLok, and then measure their bulk densities and air voids using Immersion Weighting method.

(5) Select the gradations whose air voids meet the requirements to fabricate different types of samples for different performance tests, including high-temperature stability, water stability, and fatigue resistance. Finally, the gradation whose performance is the best was selected as the optimal gradation.

\section{Raw Materials}

3.1. Asphalt Binders. Two kinds of asphalt binder were used in this paper: Shell 70-A original asphalt and SBS modified 
TABLE 1: Technical indexes of asphalt binders.

\begin{tabular}{lccc}
\hline Technical indexes & Unit & Shell 70-A & SBS modified asphalt \\
\hline Penetration $\left(25^{\circ} \mathrm{C}, 5 \mathrm{~s}, 100 \mathrm{~g}\right)$ & $0.1 \mathrm{~mm}$ & 67 & 46 \\
Softening point, R\&B & ${ }^{\circ} \mathrm{C}$ & 47.5 & 73 \\
Kinematic viscosity @ $177^{\circ} \mathrm{C}$ & $\mathrm{Pa} \cdot \mathrm{s}$ & - & 2.0 \\
Kinetic viscosity @6 $60^{\circ} \mathrm{C}$ & $\mathrm{Pa} \cdot \mathrm{s}$ & 327 & - \\
Flash point & ${ }^{\circ} \mathrm{C}$ & - & 230 \\
Elastic recovery @ $25^{\circ} \mathrm{C}$ & $\%$ & - & 83 \\
Difference of softening point for $48 \mathrm{~h}$ & ${ }^{\circ} \mathrm{C}$ & 0.10 & 2.0 \\
Mass lost & $\%$ & 65.2 & 0.12 \\
Penetration ratio, $25^{\circ} \mathrm{C}$ & $\%$ & & 79 \\
\hline
\end{tabular}

TABLE 2: Technical indexes of coarse aggregates.

\begin{tabular}{lcc}
\hline Index & Unit & Actual measurement \\
\hline Crushing value & $\%$ & 13.5 \\
Apparent relative density & - & - \\
Water absorption & $\%$ & 1.2 \\
Strength & $\%$ & 9.4 \\
Needle and plate particle content & $\%$ & 8 \\
Content of $<0.075$ mm material & $\%$ & 0.43 \\
$\begin{array}{l}\text { Adhesion with SBS modified } \\
\text { asphalt }\end{array}$ & Level & 5 \\
\hline
\end{tabular}

asphalt binder. Shell 70-A was used in the ordinary ATB-25 as the contrast material, and the SBS modified asphalt binder was used in the new designed GSOG-25. Their technical indexes were presented in Table 1.

3.2. Aggregate. The coarse aggregates, fine aggregates, and filler were produced from limestone. Their technical indexes were shown in Tables 2, 3, and 4.

\section{Proportion Design of GSOG-25 Mixtures}

4.1. Initially Designed Gradations. Through controlling the passage percent of aggregates of the four key sizes, $26.5 \mathrm{~mm}$, $9.5 \mathrm{~mm}, 4.75 \mathrm{~mm}, 0.075 \mathrm{~mm}$ sieves, and partially gapping the usage of aggregates passing sieve size of $4.75 \mathrm{~mm}$ and/or $9.5 \mathrm{~mm}, 5$ different gradations were designed initially according to Chinese Technical Specification for Construction of Highway Asphalt Pavement [32], as shown in Table 5.

In Table 5, gradations 1,3 , and 4 were partially gapped at the particle size of $4.75 \mathrm{~mm}$, and gradations 2 and 5 were partially gapped at the particle size of $9.5 \mathrm{~mm}$.

4.2. Measuring the Void of Coarse Aggregate, VCA, for Each Gradation. Dry-rodded compaction was conducted on coarse aggregates $(\geq 4.75 \mathrm{~mm})$ for each gradation, and their VCA were calculated, as shown in Table 6.

4.3. Calculating the Theoretical Voids of Each Gradation. The asphalt aggregate ratio of the mixture was estimated at $4.2 \%$, and the corresponding theoretical void of each gradation was calculated, as shown in Table 7.
From Table 7, it can be seen that the air voids of gradations 2,4 , and 5 meet the requirement. So, they were selected for further research.

4.4. The Air Voids of Fabricated Samples. For gradations 2, 4, and 5, cylinder samples were fabricated at the asphalt aggregate ratio of $4.2 \%$ using SGC. The compaction parameters of SGC were the following: compaction times, 174 times, vertical pressure, $600 \mathrm{KPa}$, and compactor angle, $1.16^{\circ}$.

The samples were vacuum sealed with CoreLok, and then their bulk density and voids were measured with Immersion Weighting method, as shown in Table 8.

It can be seen from Table 8 that the air voids of gradation 2 were very smaller than the requirement, and those of gradations 4 and 5 meet the requirements. So, gradations 4 and 5 were selected for further optimization.

4.5. Performance Tests. In order to enhance crack resistance, the asphalt aggregate ratio should be higher than ordinary ATB mixture. So, three asphalt aggregate ratios, 3.9\%, 4.2\%, and $4.5 \%$, were selected to fabricate GSOG-25 samples for both gradations (gradations 4 and 5).

The SGC cylinder samples' air voids were shown in Table 9.

(1) Moisture Susceptibility and High-Temperature Stability. High-Temperature Immersion Wheel Truck Test of Asphalt Mixtures can be used to measure the water stability and high-temperature stability of the asphalt mixture. So, the Immersion Wheel Truck Test at $60^{\circ} \mathrm{C}$ with Hamburg rutting tester was selected. The size of plate sample is $300 \mathrm{~mm} \times$ $300 \mathrm{~mm} \times 80 \mathrm{~mm}$, the samples were immersed into water at $60^{\circ} \mathrm{C}$ for 2 hours, and then the test was started. The tests were set to end when loading 30000 times or when rut depth arrived at $20 \mathrm{~mm}$. The results were shown in Table 10 .

(2) Fatigue Resistance. Four-point bending fatigue test was selected to evaluate the fatigue resistance of GSOG-25 beam sample. The size of the sample is $300 \mathrm{~mm} * 60 \mathrm{~mm} *$ $80 \mathrm{~mm}$. Because the aim of the tests is to compare the fatigue resistance of different gradation with different asphalt aggregate ratio, the fatigue loading parameters were the same: test temperature is $20^{\circ} \mathrm{C}$, loading waveform is sinusoidal wave, loading frequency $f=10 \mathrm{~Hz}$, and the cyclic Eigen value 
TABle 3: Densities of aggregates.

\begin{tabular}{lcr}
\hline Particle size $(\mathrm{mm})$ & Apparent relative density & Bulk volume relative density $\left(\mathrm{g} / \mathrm{cm}^{3}\right)$ \\
\hline 26.5 & 2.783 & 2.770 \\
19 & 2.731 & 2.716 \\
16 & 2.745 & 2.734 \\
13.2 & 2.717 & 2.693 \\
9.5 & 2.736 & 2.723 \\
4.75 & 2.696 & 2.618 \\
2.36 & 2.755 & 2.720 \\
1.18 & 2.742 & 2.695 \\
0.6 & 2.739 & 2.676 \\
0.3 & 2.759 & 2.707 \\
0.15 & 2.711 & 2.672 \\
0.075 & 2.654 & 2.609 \\
\hline
\end{tabular}

TABLE 4: Technical indexes of filler.

\begin{tabular}{lccc}
\hline Project & Unit & Test result & Specification requirements \\
\hline Apparent density & $\mathrm{t} / \mathrm{m}^{3}$ & 2.640 & $\geq 2.50$ \\
Water content & $\%$ & 0.41 & $\leq 1$ \\
Particle size range & $\%$ & 100 & 100 \\
$\quad<0.6 \mathrm{~mm}$ & $\%$ & 94.5 & $90 \sim 100$ \\
$\quad<0.15 \mathrm{~mm}$ & $\%$ & 83 & $75 \sim 100$ \\
$\quad<0.075 \mathrm{~mm}$ & - & No clustering & No clustering \\
Appearance & - & 0.6 & $<1$ \\
Hydrophilic index & - & 3 & $<4$ \\
Plasticity index & & & \\
\hline
\end{tabular}

TABLE 5: Initially designed gradations.

\begin{tabular}{lccccccccccccc}
\hline $\begin{array}{l}\text { Sieve sizes } \\
\text { (mm) }\end{array}$ & 31.5 & 26.5 & 19 & 16 & 13.2 & 9.5 & 4.75 & 2.36 & 1.18 & 0.6 & 0.3 & 0.15 & 0.075 \\
\hline Gradation 1 (\%) & 100 & 77 & 58.8 & 49.1 & 39.5 & 18.5 & 17.8 & 15 & 12 & 8 & 5.5 & 4.8 & 3.3 \\
Gradation 2 (\%) & 100 & 77 & 55.8 & 49.1 & 28.5 & 27.5 & 17.8 & 15 & 12 & 8 & 5.5 & 4.8 & 3.3 \\
Gradation 3 (\%) & 100 & 100 & 67.4 & 51.9 & 37.3 & 19.4 & 17.5 & 13.6 & 10.7 & 8.4 & 6.5 & 5.1 & 4 \\
Gradation 4 (\%) & 100 & 75.7 & 56.2 & 45.2 & 34.3 & 21 & 19.8 & 15 & 12 & 8 & 5.5 & 4.8 & 3.3 \\
Gradation 5 (\%) & 100 & 75.2 & 55.2 & 43.7 & 32.3 & 30.5 & 17.8 & 15 & 12 & 8 & 5.5 & 4.8 & 3.3 \\
\hline
\end{tabular}

$\rho=P_{\min } / P_{\max }=0.3 \mathrm{KN} / 3 \mathrm{KN}=0.1$. The fatigue results were shown in Table 11.

(3) Seepage. Seepage performance was measured on plate sample according to Chinese standard test methods of bitumen and bituminous mixtures for highway engineering [33]. The results were shown in Table 12.

4.6. Selection of Optimal Gradation. It can be seen from Table 6 that gradation 5 with $4.2 \%$ asphalt aggregate ratio has the best high-temperature stability and water stability, and gradation 4 with $4.5 \%$ asphalt aggregate ratio has the best fatigue resistance. Considering that the project is located in south China, the climate is characterized by high temperature and is rainy, so gradation 5 with $4.2 \%$ asphalt aggregate ratio was selected as the optimal gradation.

\section{Comparison of the Performances}

The performance, especially the antireflection cracking resistance of the optimized GSOG-25, was measured and compared with those of the ordinary ATB-25.

5.1. Design of the Ordinary ATB-25. The gradation of ATB25 was designed according to Chinese Technical Specification for Construction of Highway Asphalt Pavement (JTG F402004) [13], the asphalt binder is Shell 70-A, and optimal asphalt content is $3.7 \%$. Its gradation was shown in Table 13 . 
TABLE 6: The VCA of each gradation.

\begin{tabular}{lccc}
\hline Gradation & $\begin{array}{c}\text { Density at dry-rodded compaction } \\
\left(\mathrm{g} \cdot \mathrm{cm}^{-3}\right)\end{array}$ & $\begin{array}{c}\text { Bulk density of coarse aggregates } \\
\left(\mathrm{g} \cdot \mathrm{cm}^{-3}\right)\end{array}$ & $\begin{array}{c}\text { VCA } \\
(\%)\end{array}$ \\
\hline Gradation 1 & 1.942 & 2.747 & 2.739 \\
Gradation 2 & 1.916 & 2.721 & 30.05 \\
Gradation 3 & 1.863 & 2.735 & 31.5 \\
Gradation 4 & 1.829 & 2.729 & 33.1 \\
Gradation 5 & 1.864 & 31.7 \\
\hline
\end{tabular}

TABLE 7: Theoretical void of each gradation.

\begin{tabular}{lcc}
\hline Gradation & $\begin{array}{c}\text { Estimated asphalt } \\
\text { aggregate ratio } \\
(\%)\end{array}$ & $\begin{array}{c}\text { Theoretical void } \\
(\%)\end{array}$ \\
\hline Gradation 1 & 4.2 & 5.7 \\
Gradation 2 & 4.2 & 9.5 \\
Gradation 3 & 4.2 & 6.7 \\
Gradation 4 & 4.2 & 12.4 \\
Gradation 5 & 4.2 & 12.1 \\
\hline
\end{tabular}

The Marshall technological indexes of the ordinary ATB25 were shown in Table 14.

5.2. Comparison of the Performances. The performance properties of asphalt mixture include resistance to hightemperature deformation, to low-temperature cracking, to water damage, and to fatigue cracking. Considering that the ATB course usually lies $16 \mathrm{~cm}$ to $20 \mathrm{~cm}$ below the pavement surface, the low-temperature performance was not concerned in the paper. The compared performances include resistance to high-temperature deformation, to water damage, to fatigue cracking, and to antireflection crack.

(1) Resistance to High-Temperature Deformation. The rutting tests at $60^{\circ} \mathrm{C}$ were conducted to evaluate their hightemperature stability. The sample size is $300 \mathrm{~mm} * 300 \mathrm{~mm} *$ $80 \mathrm{~mm}$, compacted with kneading compactor. According to Chinese standard test methods of bitumen and bituminous mixtures (JTG E20-2011) [15], the dynamic stability index, DS, was used as the evaluation index.

$$
\mathrm{DS}=\frac{d_{2}-d_{1}}{t_{2}-t_{1}},
$$

where DS is dynamic stability, times/mm; $d_{2}$ is deformation at the moment of $t_{2}, \mathrm{~mm}$; and $d_{1}$ is deformation at the moment of $t_{1}, \mathrm{~mm}$.

The results were shown in Table 15.

It can be seen from Table 15 that the dynamic stability of GSOG-25 is obviously higher than that of ATB-25, and the rut depth of GSOG-25 is only about half of that of ATB-25. So the resistance to high-temperature deformation of GSOG-25 is obviously better than that of ATB-25.

(2) Water Stability. The residual Marshall stability, $S$, is used as the index to evaluate the water stability according to the
Chinese Technical Specification for Construction of Highway Asphalt Pavement.

Standard Marshall test and immersion Marshall test were conducted according to Chinese standard test methods of bitumen and bituminous mixtures for highway engineering, T0709-2011 [13], and then the residual stability, $S$, can be determined from the Marshall stability $S_{0}$ and the immersion Marshall stability $S_{1}$ according to formula (4).

$$
S=\frac{S_{1}}{S_{0}} \times 100 \%,
$$

where $S$ is the residual stability, $\% ; S_{1}$ is the immersion Marshall stability, $\mathrm{kN}$; and $S_{0}$ is the Marshall stability, $\mathrm{kN}$.

The results of water stability tests were shown in Table 16.

It can be seen from Table 16 that the water stability of these two designed mixtures meets the specification requirement. And the residual stability of GSOG-25 is greater than that of ATB-25, which means that the water stability of GSOG-25 is better than that of ATB-25.

(3) Fatigue Resistance. Four-point bending fatigue tests were conducted with servo material tester, UTM-100, to compare the fatigue performance of the two designed mixtures.

The size of the beam samples is $380 \mathrm{~mm} * 60 \mathrm{~mm} *$ $50 \mathrm{~mm}$. The samples were formed by using a vibration roller, HYLN-5, through a pneumatic loading, and it is a good simulation to the site situation of asphalt pavement. The test temperature is $15 \pm 0.5^{\circ} \mathrm{C}$ and loading frequency is $10 \pm 0.1 \mathrm{~Hz}$ according to Chinese standard test methods of bitumen and bituminous mixtures for highway engineering [13]. The maximum strain was controlled during the repeated loading, and the $\mathrm{N}_{\mathrm{f50}}$ method was used to determine the fatigue life, which means that when the modulus of the sample is decreased to $50 \%$ of its initial modulus, the cyclic loading times are its fatigue life. The results were given in Table 17 and were contrasted in Figure 1.

It can be seen from Table 17 and Figure 1 that the fatigue performance of GSOG-25 is much better than that of ATB-25 obviously. When the maximum strain is controlled at $400 \mu \varepsilon$, the fatigue life of GSOG-25 is about 220 times greater than that of the ordinary ATB-25. And when the strain level is controlled at $600 \mu \varepsilon$, the fatigue life of GSOG-25 is also much greater than that of the ordinary ATB-25.

(4) Antireflection Cracking Resistance. Loading mode of reflection crack resistance test shown in Figure 2 was used to measure the resistance to reflection cracking. 
TABLE 8: Measured air voids of each gradation at asphalt aggregate ratio of $4.2 \%$.

\begin{tabular}{lcccc}
\hline Gradation & $\begin{array}{c}\text { Bulk density } \\
\left(\mathrm{g} \cdot \mathrm{cm}^{-3}\right)\end{array}$ & $\begin{array}{c}\text { Theoretical maximum relative density } \\
\left(\mathrm{g} \cdot \mathrm{cm}^{-3}\right)\end{array}$ & $\begin{array}{c}\text { Void } \\
(\%)\end{array}$ & $\begin{array}{c}\text { Average void } \\
(\%)\end{array}$ \\
\hline Gradation 2 & 2.379 & 2.561 & 7.1 & 6.8 \\
& 3.386 & 2.561 & 8.4 & 7.8 \\
Gradation 4 & 2.344 & 2.558 & 7.8 & 7.9 \\
Gradation 5 & 2.358 & 2.558 & 2.1 & 8.1 \\
\hline
\end{tabular}

TABLE 9: Measured voids of ATB mixtures.

\begin{tabular}{|c|c|c|c|c|}
\hline \multirow{2}{*}{ Gradation } & \multirow{2}{*}{$\begin{array}{c}\text { Asphalt aggregate ratio } \\
(\%)\end{array}$} & \multicolumn{3}{|c|}{ Voids (\%) } \\
\hline & & Sample 1 & Sample 2 & Average \\
\hline \multirow{3}{*}{ Gradation 4} & 3.9 & 9.7 & 9.1 & 9.4 \\
\hline & 4.2 & 8.4 & 7.8 & 8.1 \\
\hline & 4.5 & 7.0 & 7.6 & 7.3 \\
\hline \multirow{3}{*}{ Gradation 5} & 3.9 & 9.5 & 9.0 & 9.2 \\
\hline & 4.2 & 7.9 & 8.1 & 8.0 \\
\hline & 4.5 & 7.4 & 6.7 & 7.1 \\
\hline
\end{tabular}

TABLE 10: Hamburg immersion rutting test results.

\begin{tabular}{lccc}
\hline Gradation & $\begin{array}{c}\text { Asphalt aggregate ratio } \\
(\%)\end{array}$ & Times & $\begin{array}{c}\text { Depth of rut } \\
(\mathrm{mm})\end{array}$ \\
\hline \multirow{3}{*}{ Gradation 4} & 3.9 & 20900 & 20 \\
& 4.2 & 30000 & 14.33 \\
Gradation 5 & 4.5 & 30000 & 12.78 \\
& 3.9 & 30000 & 12.06 \\
& 4.2 & 30000 & 7.96 \\
\hline
\end{tabular}

TABLE 11: Fatigue results.

\begin{tabular}{|c|c|c|c|c|c|}
\hline \multirow{2}{*}{ Gradation } & \multirow{2}{*}{$\begin{array}{l}\text { Asphalt aggregate ratio } \\
(\%)\end{array}$} & \multicolumn{4}{|c|}{ Fatigue life (cycles) } \\
\hline & & Sample 1 & Sample 2 & Sample 3 & Average \\
\hline \multirow{3}{*}{ Gradation 4} & 3.9 & 527 & 655 & 763 & 648 \\
\hline & 4.2 & 2289 & 1739 & 788 & 1605 \\
\hline & 4.5 & 3707 & 4344 & 1867 & 3306 \\
\hline \multirow{3}{*}{ Gradation 5} & 3.9 & 807 & 1012 & 711 & 843 \\
\hline & 4.2 & 1703 & 1309 & 1072 & 1361 \\
\hline & 4.5 & 1925 & 2090 & 1884 & 1966 \\
\hline
\end{tabular}

TABle 12: Permeability coefficient and voids of specimens.

\begin{tabular}{lccc}
\hline Gradation & $\begin{array}{c}\text { Asphalt aggregate ratio } \\
(\%)\end{array}$ & $\begin{array}{c}\text { Permeability coefficient } \\
(\mathrm{ml} / \mathrm{min})\end{array}$ & $\begin{array}{c}\text { Void } \\
(\%)\end{array}$ \\
\hline \multirow{3}{*}{ Gradation 4} & 3.9 & 420 & 9.8 \\
& 4.2 & No seepage & 9.0 \\
& 4.5 & 380 & 8.3 \\
Gradation 5 & 3.9 & 135 & 9.6 \\
& 4.2 & No seepage & 8.7 \\
\hline
\end{tabular}


TABLE 13: Gradation of ATB-25.

\begin{tabular}{lccccccccccccc}
\hline $\begin{array}{l}\text { Size of sieve } \\
(\mathrm{mm})\end{array}$ & 31.5 & 26.5 & 19 & 16 & 13.2 & 9.5 & 4.75 & 2.36 & 1.18 & 0.6 & 0.3 & 0.15 & 0.075 \\
\hline Upper limit & 100 & 100 & 90 & 76 & 62 & 52 & 40 & 29 & 25 & 18 & 14 & 10 & 6 \\
Lower limit & 100 & 90 & 70 & 55 & 42 & 32 & 20 & 14 & 10 & 8 & 5 & 3 & 2 \\
Gradation & 100 & 93.5 & 80.5 & 65.8 & 52.0 & 40.1 & 29.3 & 20.5 & 15.6 & 11.8 & 8.3 & 6.3 & 3.8 \\
\hline
\end{tabular}

TABLE 14: Marshall technological index of ATB-25.

\begin{tabular}{lccccc}
\hline & \multicolumn{3}{c}{ Technological index } & & \\
$\begin{array}{l}\text { Bulk density } \\
\left(\mathrm{g} \cdot \mathrm{cm}^{-3}\right)\end{array}$ & $\begin{array}{c}\text { Theoretical max. } \\
\text { density } \\
\left(\mathrm{g} \cdot \mathrm{cm}^{-3}\right)\end{array}$ & $\begin{array}{c}\text { void } \\
(\%)\end{array}$ & $\begin{array}{c}\text { VCA } \\
(\%)\end{array}$ & $\begin{array}{c}\text { Asphalt saturation } \\
(\%)\end{array}$ & $\begin{array}{c}\text { Stability } \\
(\mathrm{KN})\end{array}$ \\
\hline 2.447 & 2.571 & 3.6 & 12.0 & 69.6 & 3.10 \\
\hline
\end{tabular}

TABLE 15: Rutting test results.

\begin{tabular}{lcccc}
\hline Index & $d_{1}(\mathrm{~mm})$ & $d_{2}(\mathrm{~mm})$ & DS (cycles/mm) & Average (cycles/mm) \\
\hline GSOG-25 & & & & 3620 \\
1 & 2.189 & 2.363 & 3020 & 3320 \\
2 & 2.283 & 2.499 & & 1097 \\
ATB-25 & & & 1139 & 1054 \\
1 & 4.710 & 5.263 & 5.423 & \\
2 & 4.825 & 5.42 & \\
\hline
\end{tabular}

TABLE 16: Residual stability of different mixtures.

\begin{tabular}{lccc}
\hline Mixture & Marshall stability $(\mathrm{kN})$ & Immersion stability $(\mathrm{kN})$ & Residual stability $(\%)$ \\
\hline ATB-25 & 3.10 & 2.74 & 88.4 \\
GSOG-25 & 8.13 & 8.05 & 99.0 \\
\hline
\end{tabular}

TABLE 17: Fatigue lives of different mixtures.

\begin{tabular}{|c|c|c|c|c|}
\hline Index & $\begin{array}{c}\text { Strain level } \\
(\mu \varepsilon)\end{array}$ & $\begin{array}{l}\text { Initial modulus } \\
\qquad(\mathrm{MPa})\end{array}$ & $\begin{array}{c}\text { Fatigue life } \\
\text { (cycles) }\end{array}$ & $\begin{array}{c}\text { Average value } \\
\text { (cycles) }\end{array}$ \\
\hline \multirow{4}{*}{ GSOG-25 } & \multirow{2}{*}{400} & 4676 & 467090 & \multirow{2}{*}{441465} \\
\hline & & 4568 & 415840 & \\
\hline & \multirow{2}{*}{600} & 5032 & 154920 & \multirow{2}{*}{162015} \\
\hline & & 4088 & 169110 & \\
\hline \multirow{3}{*}{ ATB-25 } & \multirow{2}{*}{400} & 6577 & 21010 & \multirow{2}{*}{23385} \\
\hline & & 3952 & 25760 & \\
\hline & 600 & 7453 & 3030 & 3305 \\
\hline
\end{tabular}

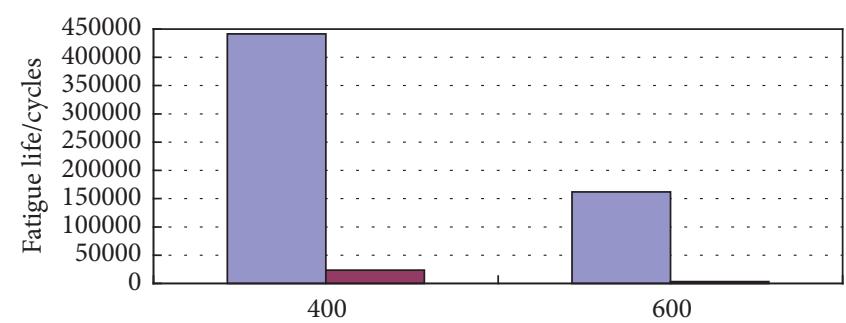

$(\mu \varepsilon)$

GSOG-25

- ATB-25

FIGURE 1: Comparison of fatigue lives of the two mixtures. 


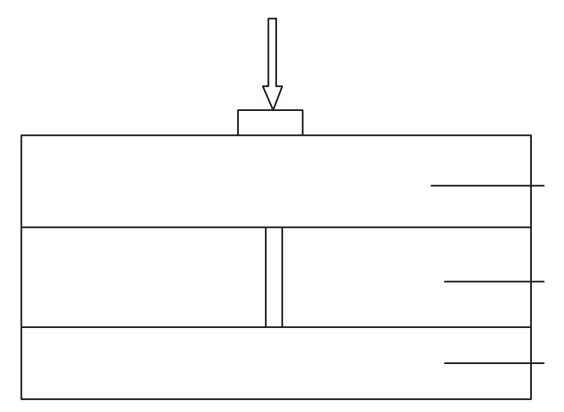

(a) Flexural tensile reflection crack

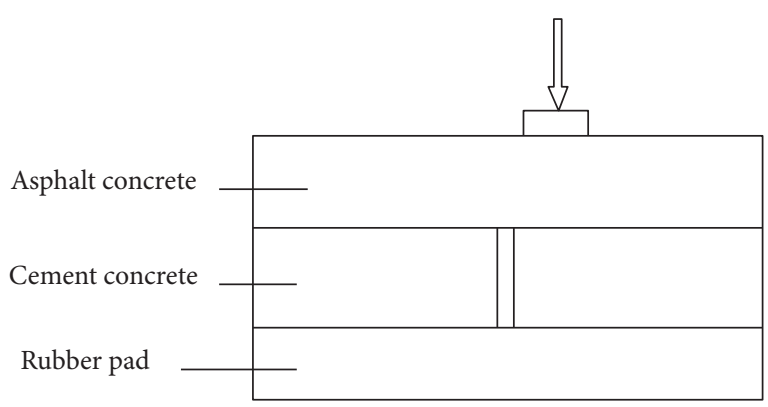

(b) Shear reflection crack

FIGURE 2: Reflection crack resistance test loading mode.

TABLE 18: Flexural tensile type reflection crack.

\begin{tabular}{lcccc}
\hline Mixture & Sample & $\begin{array}{c}\text { Initial crack } \\
\left(* 10^{4} \text { cycles }\right)\end{array}$ & $\begin{array}{c}\text { Total life } \\
\left(* 10^{4} \text { cycles }\right)\end{array}$ & $\begin{array}{c}\text { Average }\left(* 10^{4} \text { cycles }\right) \\
\text { Total life } \\
\text { Initial crack }\end{array}$ \\
\hline \multirow{3}{*}{ ATB-25 } & 1 & 0.56 & 14.6 & 0.63 \\
& 2 & 0.74 & 18.6 & 16.05 \\
& 3 & 0.68 & 15.9 & 0.7 \\
GSOG-25 & 1 & 0.54 & 26.3 & 28.3 \\
& 2 & 0.68 & 10.6 & 2.1 \\
\end{tabular}

TABLE 19: Shearing type reflection crack.

\begin{tabular}{lcccc}
\hline Mixture & Sample & $\begin{array}{c}\text { Initial crack } \\
\left(* 10^{4} \text { cycles }\right)\end{array}$ & $\begin{array}{c}\text { Total life } \\
\left(* 10^{4} \text { cycles }\right)\end{array}$ & $\begin{array}{c}\text { Average }\left(* 10^{4} \text { cycles }\right) \\
\text { Total life }\end{array}$ \\
\hline \multirow{2}{*}{ ATB-25 } & 1 & 0.62 & 15.8 & 0.55 \\
& 2 & 0.45 & 9.4 & 12.45 \\
& 3 & 0.56 & 11.5 & 0.77 \\
GSOG-25 & 1 & 0.58 & 21.1 & 20.7 \\
& 2 & 0.9 & 24.2 & 19.4 \\
\end{tabular}

The sample is a compound sample, which is compounded with ATB layer, cement concrete layer (with a prefabricated crack), and rubber pad. The dimensions of compound sample are as follows: $30 \mathrm{~cm}$ (length) $* 6 \mathrm{~cm}$ (width) $* 20 \mathrm{~cm}$ (thickness). The thickness of the compound sample is consisting of $8 \mathrm{~cm}$ ATB layer, $10 \mathrm{~cm}$ cement concrete, and $2 \mathrm{~cm}$ rubber pad. The width of the prefabricated crack is $1 \mathrm{~cm}$. The rubber pad is used to simulate the subgrade, and the cement concrete bricks were used to simulate cracked semirigid base course. The loading pad is $2 \mathrm{~cm} * 6 \mathrm{~cm}$, and the vertical pressure is $0.7 \mathrm{MPa}$.

The loading mode has two different modes, symmetrical loading for simulate flexural tensile reflection cracking and loading at the edge of one side of prefabricated crack for simulate shear reflection cracking.
The cracking test results of ATB-25 and GSOG-25 at different loading modes were shown in Tables 18 and 19.

It can be seen from Tables 18 and 19 that the optimized GSOG-25 has better reflection crack resistance than ordinary ATB-25. Their initial crack loading cycles are almost the same, but the total life of GSOG-25 is much greater than that of ATB-25.

\section{Conclusion}

In order to improve the reflection crack resistance of ATB, the requirements of the mixture and gradation characteristics were put forward, and the gradation design procedures were put forward based on the volume design method and performances tests. And a type of GSOG-25 mixture was optimized 
according to the design procedures. Comprehensive performance tests, including rutting test, water stability test, fatigue test, and reflection crack test, were conducted on the ordinary ATB-25 and the optimized GSOG-25. The results indicated that the performance of GSOG-25 is superior to ATB-25; its reflection crack resistance has been enhanced much, which meets the purpose of the paper.

\section{Conflicts of Interest}

The authors declare that there are no conflicts of interest regarding the publication of this paper.

\section{References}

[1] L. E. I. Wenmao, Structural Analysis on Long-Life Asphalt Pavement with Compound Base Courses, Central South University, 2010.

[2] J. Chen, Study on the Structure of Asphalt Pavement and Material under Heavy Loads in Shanxi, Chang'an University, Xian, China, 2012.

[3] Z. Li, Study on Structure and Material of Compound Base Asphalt Pavement, Chang'an University, Xian, China, 2008.

[4] Y.-y. Li, "Evaluation and analysis on the impact of base combination to asphalt pavement," Science Technology and Engineering, vol. 12, no. 2, pp. 214-216, 2012.

[5] L. Li, Z. He, X. Zhang et al., "Mechanical property of rutting resistant and flexible base asphalt mixture," Journal of Materials Science \& Engineering, vol. 32, no. 5, pp. 137-146, 2014.

[6] R. D. Barksdale, J. Alba, N. P. Khosla, R. Kim, P. C. Lambe, and M. S. Rahman, "Laboratory determination of resilient modulus for flexible pavement design," NCHRP Report 1-28, Transportation Research Board, Washington, DC, USA, 2004.

[7] K. M. Muthen, Foamed asphalt mixes mix design procedure, SABITA Ltd and CSIR Transportek, Pretoria, South Africa, 1998.

[8] I. M. Asi, "Stabilization of sebkha soil using foamed asphalt," Journal of Materials in Civil Engineering, vol. 13, no. 5, pp. 325331, 2001.

[9] A. Nataatmadja, "Some characteristics of foamed bitumen mixes," Transportation Research Record, Transportation Research Board, Washington, DC, USA, 2001.

[10] Y. Kim and H. D. Lee, "Development of mix design procedure for cold in-place recycling with foamed asphalt," Journal of Materials in Civil Engineering, vol. 18, no. 1, pp. 116-124, 2006.

[11] M. F. Saleh, "Effect of rheology on the bitumen foamability and mechanical properties of foam bitumen stabilised mixes," International Journal of Pavement Engineering, vol. 8, no. 2, pp. 99-110, 2007.

[12] R. S. Gartin and D. C. Esch, Treated Base Course Performance in Alaska, Alaska DOT and Public Facilities, Juneau, Alaska, USA, 1991.

[13] A. Loizos and V. Papavasiliou, "Evaluation of foamed asphalt cold in-place pavement recycling using nondestructive techniques," Journal of Transportation Engineering, vol. 132, no. 12, pp. 970-978, 2006.

[14] K. Yongjoo, D. L. Hosin, and M. Heitzman, "Validation of new mix design procedure for cold in-place recycling with foamed asphalt," Journal of Materials in Civil Engineering, vol. 19, no. 11, pp. 1000-1010, 2007.
[15] J. R. Anderson and M. R. Thompson, "Characterization of emulsion aggregate mixtures," Transportation Research Record, Transportation Research Board, Washington, DC, USA, 1995.

[16] M. J. Farrar and K. Ksaibati, "Resilient modulus testing of lean emulsified asphalt," Transportation Research Record 1546, Transportation Research Board, Washington, DC, USA, 1996.

[17] C. Berthelot, B. Marjerison, G. Houston, J. McCaig, S. Warrener, and R. Gorlick, "Mechanistic comparison of cement- and bituminous-stabilized granular base systems," Transportation Research Record, vol. 2026, pp. 70-80, 2007.

[18] C. W. Schwartz and S. Khosravifar, Design and Evaluation of Foamed Asphalt Base Materials, University of Maryland, College Park, Md, USA, 2013.

[19] C. P. Wang, "Performance-based mixture design of asphalttreated base," Journal of the Institution of Engineers, vol. 4, no. 2, pp. 176-181, 2004.

[20] P. Li, J. Liu, and S. Saboundjian, "Materials and temperature effects on the resilient response of asphalt-treated alaskan base course materials," Journal of Materials in Civil Engineering, vol. 23, no. 2, pp. 161-168, 2011.

[21] A. H. Hector, "Development of a new mix design method and specification requirements for asphalt treated bases," Tech. Rep., The University of Texas, El Paso, Tex, USA, 2011.

[22] Y. Zhang, L. Wang, B. Diefenderfer, and W. Zhang, "Determining volumetric properties and permeability of asphalt-treated permeable base mixtures," International Journal of Pavement Engineering, vol. 17, no. 4, pp. 343-352, 2016.

[23] S. W. Haider, K. Chatti, N. Buch, R. W. Lyles, A. S. Pulipaka, and D. Gilliland, "Effect of design and site factors on the long-term performance of flexible pavements," Journal of Performance of Constructed Facilities, vol. 21, no. 4, pp. 283-292, 2007.

[24] W. Dong, F. Yang, C. Tang et al., Construction of Asphalt Stabilized Macadam in Nanchong-Guangan Expressway, vol. 4, Xi'nan Highway, 2003.

[25] X. Feng and P. Hao, "Gradation design method of dense-graded asphalt stabilized macadam base," China Journal of Highway and Transport, vol. 22, no. 4, pp. 33-38, 2009.

[26] Z. Ge, R. Qian, L. Qian, J. Zhang, and W. Zhang, "Fatigue performance of asphalt stabilized macadam," East China Highway, vol. 130, no. 3, pp. 62-66, 2001.

[27] Z.-D. Qian and F.-M. Shu, "Performance experiments of highmodulus asphalt treated base," Journal of Traffic and Transportation Engineering, vol. 9, no. 3, pp. 28-32, 2009.

[28] L. Tian, Research on Anti-Cracking Characteristics of FrameDense Cement Stabilized Graded Crushed Stone, Harbin Institute of Technology, Harbin, China, 2010.

[29] K. Wu and X. Zhang, "Design of dense gap-graded friction course mixture," Journal of Southeast University, vol. 22, no. 1, pp. 101-105, 2006.

[30] G. Liu, "On the component design of gap-graded bituminous mixture," Journal of Hefei University of Technology, vol. 27, no. 4, pp. 446-449, 2004.

[31] D. Feng, F. Yu, and C. Gong, "Mix design method of cement stabilized grade crushed stone based on volume method," Journal of Highway and Transportation Research and Development, vol. 29, no. 10, pp. 22-32, 2012.

[32] JTG F40-2004, Technical Specification for Construction of Highway Asphalt Pavement, China Communications Press, Beijing, China, 2004.

[33] JTG E20-2011, Standard Test Methods of Bitumen and Bituminous Mixtures for Highway Engineering, China Communications Press, Beijing, China, 2011. 

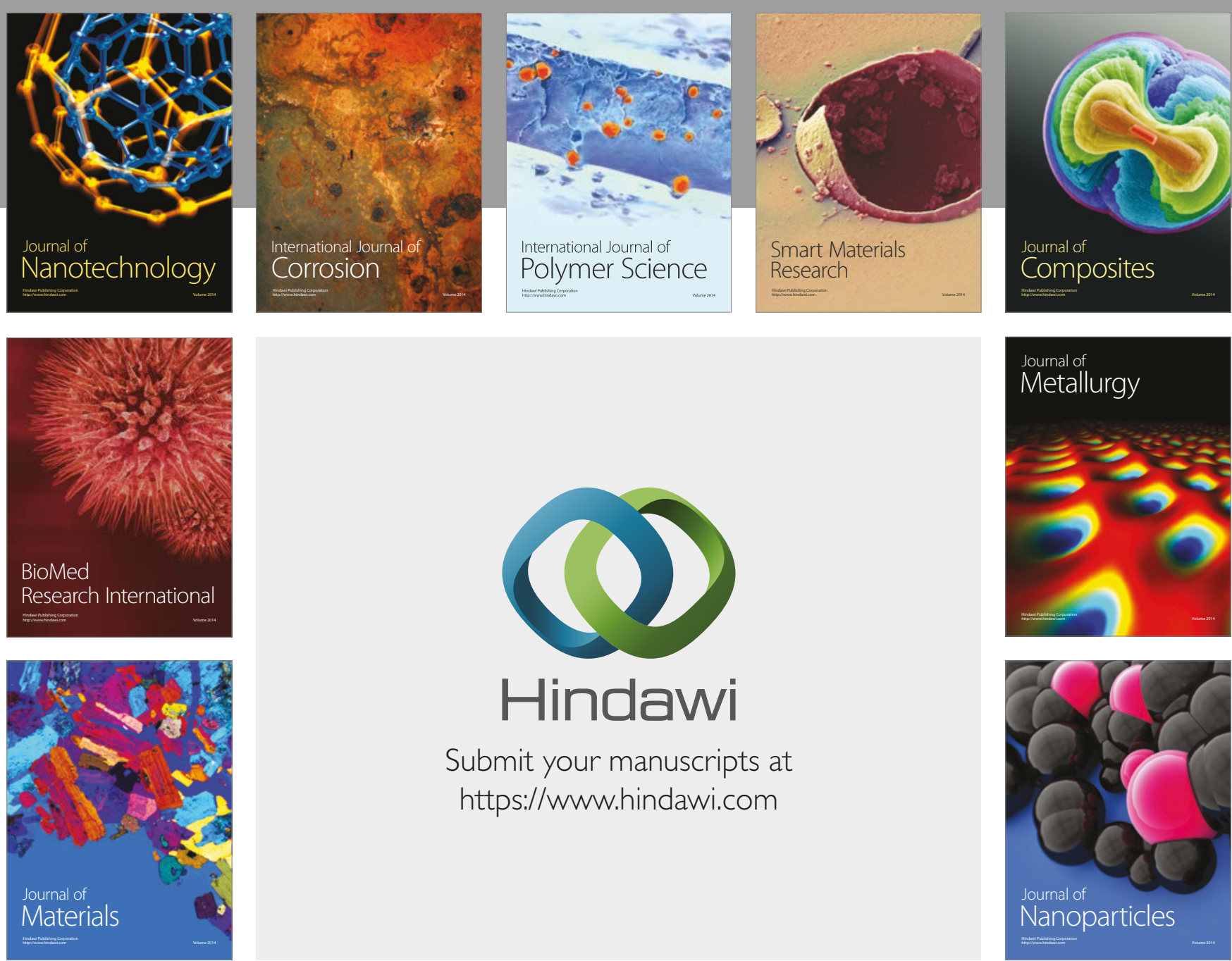

\section{Hindawi}

Submit your manuscripts at

https://www.hindawi.com
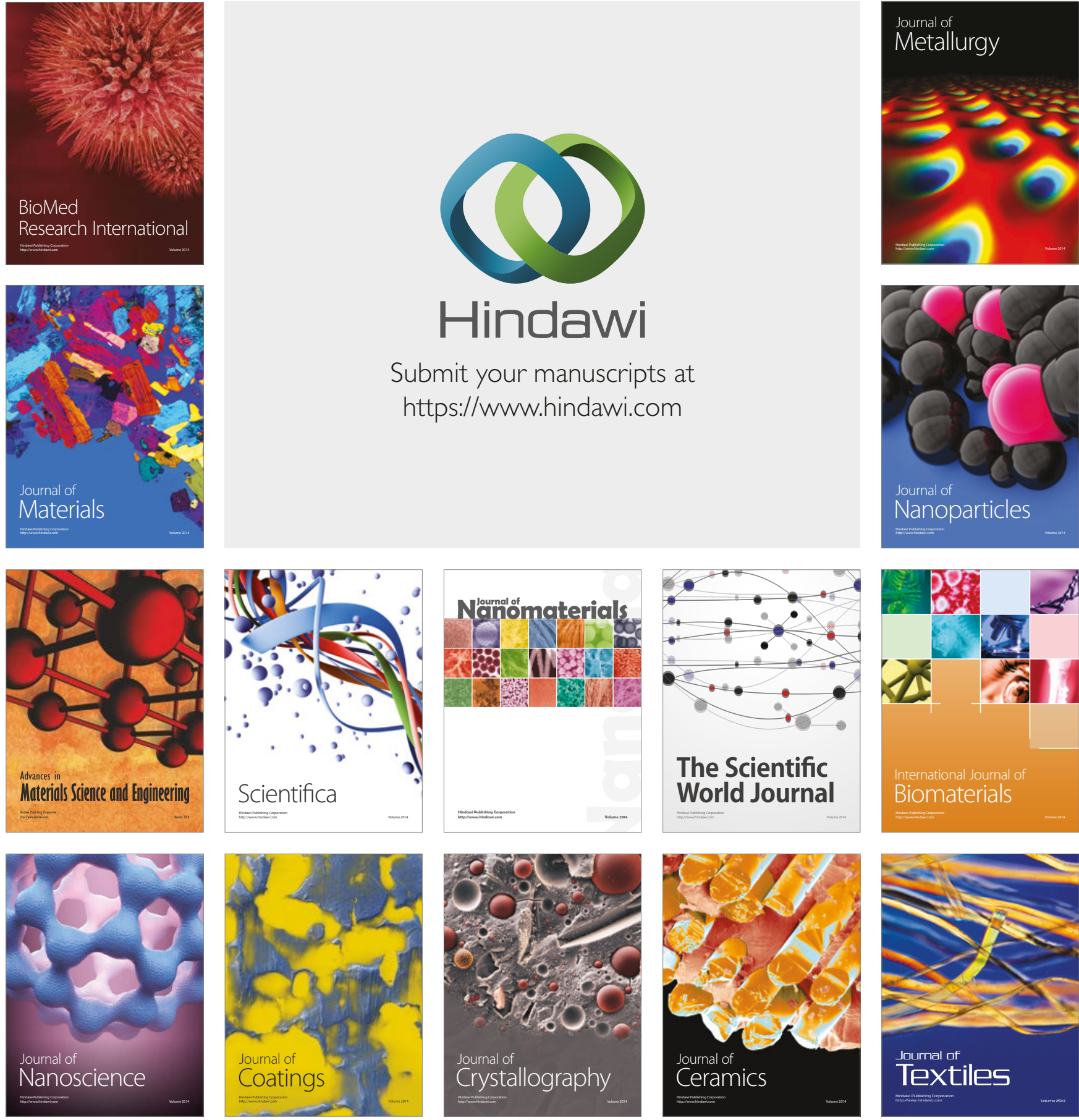

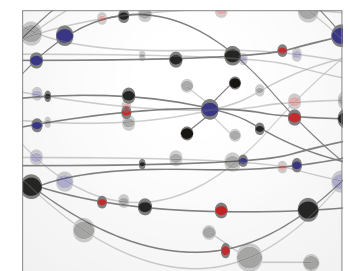

The Scientific World Journal
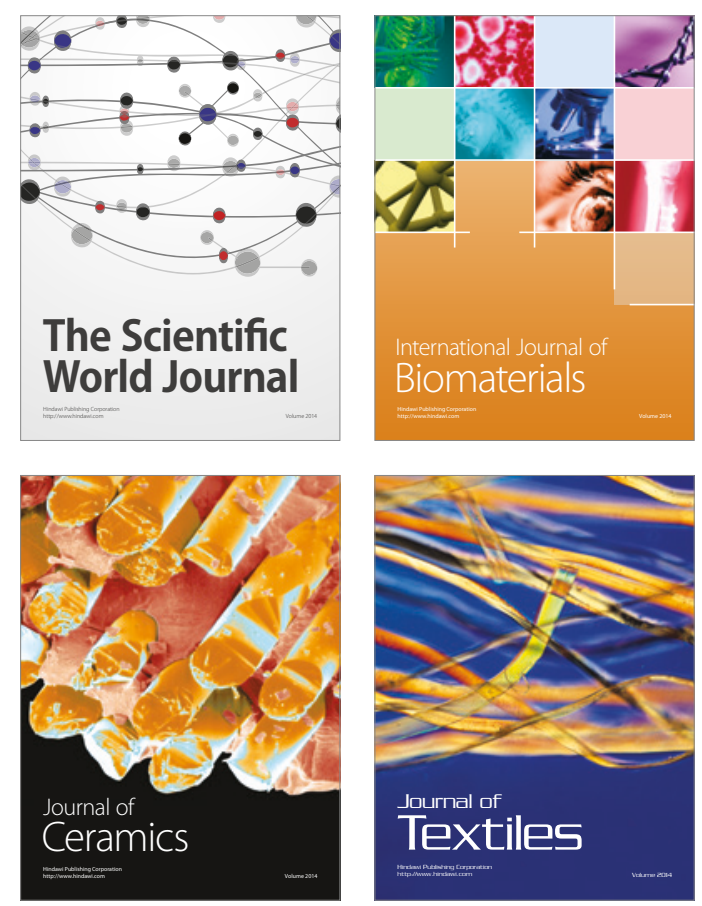